\title{
Early age at first sexual intercourse and early pregnancy are risk factors for cervical cancer in developing countries
}

\author{
KS Louie*,1, S de Sanjose ${ }^{1,2}$, M Diaz', X Castellsaguél,2 ${ }^{1,}$ R Herrero ${ }^{3}$, CJ Meijer ${ }^{4}$, K Shah $^{5}$, S Franceschi $^{6}$, \\ N Muñoz ${ }^{7}$ and FX Bosch' for the International Agency for Research on Cancer Multicenter Cervical Cancer \\ Study Group
}

'Unit of Infections and Cancer, Cancer Epidemiology Research Program, Catalan Institute of Oncology, Hospitalet del Llobregat (Barcelona), Avda. Gran Via sln Km 2,7, Barcelona 080907, Spain; ${ }^{2}$ CIBER en Epidemiología y Salud Pública (CIBERESP), Barcelona, Spain; ' ${ }^{3}$ royecto Epidemiológico Guanacaste, Fundación INCIENSA, Torre La Sabana, 300 Oeste del ICE, Piso 7, Sabana Norte, San José, Costa Rica; ${ }^{4}$ Department of Pathology, VY University Medical Center, PO Box 7057, 1007 MB Amsterdam, The Netherlands; ${ }^{5}$ Department of Molecular Microbiology and Immunology, Johns Hopkins Bloomberg School of Public Health, Baltimore, MD, USA; 'International Agency for Research on Cancer, 150 cours Albert Thomas, 69372 Lyon cedex 08, France; ' Instituto Nacional de Cancerologia, Bogotá, Colombia

Early age at first sexual intercourse (AFSI) has long been associated with an increased risk of invasive cervical carcinoma (ICC). Age at first pregnancy (AFP) and ICC have been investigated less, although AFSI and AFP are strongly interrelated in most developing countries. A pooled analysis of case-control studies on ICC from eight developing countries with I864 cases and I7I9 controls investigated the roles of AFSI, AFP, and ICC risk. Age at first sexual intercourse, AFP and age at first marriage (AFM) were highly interrelated and had similar ICC risk estimates. Compared with women with AFSI $\geqslant 21$ years, the odds ratio (OR) of ICC was I.80 (95\% Cl: I.50-2.39) among women with AFSI $17-20$ years and 2.31 (95\% Cl: $1.85-2.87)$ for AFSI $\leqslant 16$ years $(P$-trend $<0.001)$. No statistical interaction was detected between AFSI and any established risk factors for ICC. The ICC risk was 2.4-fold among those who reported AFSI and AFP at $\leqslant 16$ years compared with those with AFSI and AFP at $\geqslant 21$ years. These data confirm AFSI and AFB as risk factors for ICC in eight developing countries, but any independent effects of these two events could not be distinguished. British Journal of Cancer (2009) I 100, I I9I-I 197. doi: I0.1038/sj.bjc.6604974 www.bjcancer.com

Published online 10 March 2009

(c) 2009 Cancer Research UK

Keywords: cervical cancer; first sexual intercourse; pregnancy; sexual behaviour; child sexual abuse

Early age at first sexual intercourse (AFSI) has been associated with an increased risk of high-risk human papillomavirus (HPV) infection, a sexually transmitted infection (STIS), that in susceptible women is responsible for virtually all cases of invasive cervical cancer (ICC) (Bosch et al, 2002). As sexual behaviour determines exposure to HPV, AFSI is of particular interest as it has been associated with riskier sexual behaviour, such as having unprotected sex, having multiple sexual partners, as well as a woman's partner having multiple partners. It has also been speculated that the increased risk of HPV is because of a biological predisposition of the immature cervix during adolescence that may be more susceptible to persistent HPV infections and therefore have a greater risk of cancer development (Kjaer et al, 1998). A number of studies have identified an increased risk of high-grade lesions and/or cervical cancer with early AFSI, whereas others have not (IARC, 2007). However, many of these studies were conducted before HPV assessment was feasible, and therefore, the association remains inconclusive. Age at first marriage (AFM) is often used as a

*Correspondence: KS Louie, Unit of Infections and Cancer, Cancer Epidemiology Research Program, Institut Catalá d'Oncologia, Avda. Gran Via s/n Km 2,7, Hospitalet de Llobregat, Barcelona 80907, Spain; E-mail: klouie@iconcologia.net

Received 22 January 2009; revised 13 February 2009; accepted 16 February 2009; published online 10 March 2009 proxy measure for AFSI, and those who engage in early sexual intercourse may also consequently become pregnant at an early age. Besides early AFSI, early childbearing has also been linked as a risk factor for cervical carcinogenesis and attributed to the cervical trauma experienced during early age at first pregnancy (AFP), or subsequently, by high-parity births (IARC, 2007). The interpretation of the mechanisms by which these sexual and reproductive events occurring early in life might affect ICC risk three or more decades later is not straightforward. The objective of this study is to further characterise and provide robust estimates of the risk of cervical cancer and its association with AFSI, interrelated characteristics such as AFP and AFM in a series of studies that fully considered the association of HPV with cervical cancer.

\section{MATERIALS AND METHODS}

The programme of HPV and cervical cancer studies has been coordinated by the International Agency for Research on Cancer (IARC) in Lyon, France and the Institut Català d'Oncologia (ICO) in Barcelona, Spain. They included a series of case-control studies on ICC from eight developing countries with a broad range of rates of incidence of cervical cancer that were pooled for analysis. Regions covered include Morocco (Chaouki et al, 1998) and Algeria (Hammouda et al, 2005) in Africa; the Philippines (Ngelangel et al, 1998), Thailand (Chichareon et al, 1998) and 
Madras in Asia; and Brazil (Eluf-Neto et al, 1994), Colombia (Munoz et al, 1993), Paraguay (Rolon et al, 2000) and Peru (Eluf-Neto et al, 1994) in South America. Although Spain (Munoz et al, 1993) was part of the series of case-control studies, the sexual and reproductive behaviour of this population was heterogeneous to the other countries (late AFSI and low parity) and the study site was therefore excluded from this analysis.

The methods of each study have been described elsewhere. Briefly, women with histologically confirmed incident invasive squamous cell carcinoma (SCC), adenocarcinoma or adenosquamous-cell carcinoma were recruited from reference hospitals before treatment. Written informed consent was obtained from those who agreed to participate. Hospital-based controls were frequency-matched to case patients by 5-year age groups.

A standardised questionnaire was administered to the participants by a trained interviewer, which included questions about sociodemographic factors, sexual and reproductive behaviour, smoking habits, pap screening history, hygienic practices, and history of sexually transmitted diseases.

Two samples of cervical exfoliated cells were collected with wooden spatulae and endocervical brushes. After preparation of one Papanicolaou smear, the remaining cells were eluded in saline, centrifuged and frozen at $-70^{\circ} \mathrm{C}$ until shipment to the central laboratory for HPV DNA testing. A tumor-biopsy sample was obtained from cases and frozen. Cytology and histology diagnoses were reviewed and confirmed by a panel of expert pathologists that agreed on a diagnosis by consensus or majority.

Detailed descriptions of the polymerase-chain-reaction (PCR) assays used in these studies have been described elsewhere. HPV DNA detection was detected by PCR amplification of a small fragment of the $L 1$ gene using MY09 and MY11 consensus primers for the study in Colombia (Hildesheim et al, 1994) and the GP5 $+16+$ general primer system for the other studies (Walboomers et al, 1992; Jacobs et al, 1995; Roda Husman et al, 1995). $\beta$-Globin primers were used to amplify the $\beta$-globin gene to assess the quality of the DNA in the specimen. HPV DNA in PCR products was analysed using a cocktail of HPV-specific probes and genotyped by hybridisation with type-specific probes for $33 \mathrm{HPV}$ types. Samples that tested positive for HPV DNA but did not hybridise with any of the type-specific probes were labelled as HPV X.

\section{Statistical analysis}

Unconditional logistic regression was used to estimate odds ratios (ORs) and $95 \%$ confidence intervals (95\% CI). To assess the association of AFSI with the risk of ICC, three different statistical models to adjust for HPV DNA detection were computed and compared: (1) one model included all patients and controls, and it was not adjusted for HPV DNA status, (2) a second model included all patients and controls, and included a variable to adjust for HPV DNA status, and (3) a third model was restricted to HPV - DNApositive cases and controls. To control for potential confounding, final models were adjusted for age $(<40, \geqslant 40)$, country, lifetime number of sexual partners $(1,>1)$, parity $(0,1-4, \geqslant 5)$, and educational level (never, primary, secondary or higher). Each variable included in the adjustment models was assessed for interaction with AFSI. Test for trend was carried out when appropriate, using the log-likelihood-ratio test. Only subjects who reported ever having been married and/or ever having had children were included in the analyses of AFM and AFP.

We evaluated other potential confounding factors such as smoking (never, ever), oral contraceptive use (never, 1-4 years, $\geqslant 5$ years), history of pap smears excluding those in the 12 months before enrolment (never, ever), having had first sexual intercourse before menarche and the timing of first sexual intercourse relative to age at menarche (data not shown), but they were not adjusted for in the final analysis as they did not contribute any change to the OR estimates for AFSI in the adjusted models.

\section{RESULTS}

Table 1 describes some characteristics of the 1864 ICC cases and 1719 corresponding controls that entered the final analysis. Ninety-five percent of case patients and 17\% of controls tested positive for HPV DNA. The majority of cases (92\%) had SCC. Case patients were older than controls with a median age of $49 v \mathrm{~s} 48$, respectively. Median AFSI was earlier in case patients (17 years) compared with controls (19 years), and this was found to be consistent in each country.

Table 2 shows the risk of ICC by AFSI according to the three different adjustment models. An increased risk of ICC was consistently observed with decreasing AFSI ( $P$-trend $<0.001)$. Compared with AFSI $\geqslant 21$ years, the OR of ICC was 1.80 (95\% CI: $1.50-2.16)$ for AFSI 17-20 years, and 2.31 (95\% CI: $1.85-2.87)$ for AFSI $\leqslant 16$ years, after adjusting for age, centre, lifetime number of partners, parity, and education level in the HPV-unadjusted model. According to the different model adjustments, women reporting AFSI $\leqslant 16$ years of age had a $2.3-2.5$-fold risk of ICC and 1.8-2.1-fold risk for AFSI 17-20 years of age (Table 2). Given the consistent association of AFSI and the risk of ICC across the different models, HPV-unadjusted models were used for the remainder of the results.

We calculated the risk of ICC for each country study, and, in general, each study showed an increasing risk of ICC with decreasing AFSI (data not shown). There was no evidence of heterogeneity with respect to study country $(P=0.58)$.

Table I Characteristics of cases of invasive cervix carcinoma and controls

\begin{tabular}{|c|c|c|c|c|c|c|c|c|c|c|}
\hline & \multicolumn{2}{|c|}{ HPV tested } & \multicolumn{4}{|c|}{ HPV positive } & \multicolumn{2}{|c|}{$\operatorname{Age}^{a}$} & \multicolumn{2}{|c|}{ Age at sexual debut ${ }^{a}$} \\
\hline & Cases & Controls & Cases & $\%$ & Controls & $\%$ & Cases & Controls & Cases & Controls \\
\hline Country & 1864 & 1719 & 1769 & 94.9 & 285 & 16.6 & 49 & 48 & 17 & 19 \\
\hline Algeria & 142 & 145 & 132 & 93.0 & 18 & 12.4 & 53.5 & 52 & 16 & 18 \\
\hline Morocco & 188 & 176 & 182 & 96.8 & 38 & 21.6 & 49 & 40 & 16 & 18 \\
\hline Madras (India) & 187 & 184 & 180 & 96.3 & 51 & 27.7 & 48 & 46.5 & 17 & 18 \\
\hline Philippines & 364 & 380 & 349 & 95.9 & 35 & 9.2 & 47.5 & 47 & 19 & 21 \\
\hline Thailand & 378 & 259 & 363 & 96.0 & 41 & 15.8 & 49.5 & 50 & 18 & 20 \\
\hline Brazil & 187 & 190 & 181 & 96.8 & 32 & 16.8 & 51 & 52 & 18 & 19 \\
\hline Colombia & 110 & 124 & 87 & 79.1 & 21 & 16.9 & 46 & 45.5 & 17 & 18 \\
\hline Paraguay & 112 & 86 & 109 & 97.3 & 18 & 20.9 & 48.5 & 45.5 & 16 & 19 \\
\hline Peru & 196 & 175 & 186 & 94.9 & 31 & 17.7 & 48 & 48 & 16 & 18 \\
\hline
\end{tabular}

Abbreviation: HPV = human papillomavirus. ${ }^{\text {a Median. }}$ 
Table 2 Effect of different strategies of multivariate model adjustments on the association between age at first sexual intercourse and risk of ICC (from IARC case-control studies)

\begin{tabular}{|c|c|c|c|c|c|c|}
\hline Sexual debut & Cases n (\%) & Controls n (\%) & $\begin{array}{l}\text { Age and centre adjusted } \\
\text { Odds ratio }(95 \% \mathrm{Cl})\end{array}$ & $\begin{array}{l}\text { HPV unadjusted }{ }^{a} \\
\text { Odds ratio }(95 \% \mathrm{Cl})\end{array}$ & $\begin{array}{c}\text { HPV adjusted } \\
\text { Odds ratio }(95 \% \mathrm{Cl})\end{array}$ & $\begin{array}{l}\text { HPV-positive only } \\
\text { Odds ratio }(95 \% \mathrm{Cl})\end{array}$ \\
\hline $\begin{array}{l}\geqslant 21 \text { years } \\
17-20 \text { years } \\
\leqslant 16 \text { years } \\
P \text {-trend }\end{array}$ & $\begin{array}{l}341(16.9) \\
813(40.2) \\
710(35.1)\end{array}$ & $\begin{array}{l}656(35.4) \\
667(36.0) \\
396(21.4)\end{array}$ & $\begin{array}{c}1.00 \\
2.44(1.07-2.87) \\
4.09(3.38-4.94)\end{array}$ & $\begin{array}{c}1.00 \\
1.80(1.50-2.16) \\
2.31(1.85-2.87) \\
<0.001\end{array}$ & $\begin{array}{c}1.00 \\
1.78(1.32-2.39) \\
2.09(1.48-2.96) \\
<0.001\end{array}$ & $\begin{array}{c}1.00 \\
2.10(1.49-2.97) \\
2.48(1.65-3.73) \\
<0.001\end{array}$ \\
\hline
\end{tabular}

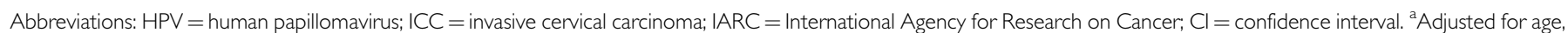
study country, lifetime number of partners $(1, \geqslant 2)$, parity $(0,1-4, \geqslant 5)$, and education (never, primary, secondary).

We stratified the analysis according to the established risk factors for ICC and the positive association of ICC with decreasing AFSI remained at each level of exposure for each of these characteristics (Table 3). Similar associations were observed for AFP. No interaction was observed between any of the examined risk factors and AFSI. Although not statistically significant, the risk linked to AFSI seemed to be stronger among parous women compared with nulliparous women.

Age at first pregnancy and AFM were both directly correlated with AFSI in these populations $(P<0.001)$. Approximately, $92 \%$ of women reported AFSI to be the same as AFM. One-quarter of women reported AFP to be the same as AFSI. Cumulatively, $62.4 \%$ of women reported giving birth within the first year of AFSI. Among women with AFSI $\leqslant 16$ years, $52.4 \%$ were pregnant within the first year of sexual intercourse. Figure 1 shows the high correlation between AFSI and AFP, and the similar decreasing risk of ICC with increasing age of AFSI/AFP. Given the high correlation between the two variables, we did not adjust for AFSI in the AFP final model and vice versa.

We further evaluated the combined effect of AFP and AFSI on the risk of cervical cancer (Table 4). An increased risk emerged in subsequent strata of decreasing AFP with decreasing AFSI. Given this combined effect, we assessed the latency period (AFP-AFSI) between these two events to clarify whether it affected the cervical cancer risk. Although there was no statistical difference across strata, the data suggested that within each AFSI strata, women with a latency period for a subsequent pregnancy of $<2$ years may be at a slight increased risk compared with women with a larger time gap (data not shown).

\section{DISCUSSION}

The IARC/ICO series of case-control studies remain the largest set of aetiological investigations on ICC that fully addresses the role of HPV DNA and of the independent established cofactors. This is probably also the largest dataset reporting on ICC in the developing world in which early AFSI, AFP and high parity are prevalent phenomenons. The results show that early AFSI and early AFP are risk factors for cervical cancer, irrespective of other known risk factors for the disease. The data presented show a possible additional increase in risk when the early event of first sexual intercourse is shortly followed by a pregnancy.

The mechanism by which the early experience of first sexual intercourse and first pregnancy could influence the risk of cervical carcinogenesis may be explained by the steroid hormonal influence on HPV infection and on the host's immune response to HPV during pre-adolescence and adolescence. The transformation zone of the cervical epithelium has been recognised as the site in which HPV infection tends to cause cancer, and the susceptibility of this area is believed to be related to its denudation of the stratified epithelium, thus facilitating exposure of the basal layer to HPV with minimal trauma. Biological immaturity during adoles- cence has also been proposed as an additional susceptibility factor (Moscicki et al, 1989; Elson et al, 2000; Singer and Monaghan, 2000). During adolescence and pregnancy, the cervix is exposed to augmented levels of hormonal changes (Singer and Monaghan, 2000), in which oestrogen stimulation facilitates acidification of the vaginal cavity, a determinant of squamous metaplasia when the endocervical epithelial everts (Elson et al, 2000). When this oestrogen-stimulated metaplastic transformation occurs in the presence of HPV, the probability of cell transformation increases, resulting in neoplastic changes (Elson et al, 2000; Shai et al, 2007, 2008; Hwang et al, 2009). This phenomenon is dependent primarily on parity, and is more likely to occur during the first pregnancy rather than subsequent pregnancies (Singer and Monaghan, 2000). Although it has been postulated that these metaplastic changes are also influenced by the trauma and repair experienced during delivery, no increased risk for cervical carcinoma was observed in this same dataset when traumatic partition was evaluated (Munoz et al, 2002).

Increased risks of cervical carcinoma have been identified in women with long-term use of hormonal steroids (Moreno et al, 2002) and those who are highly parous (Munoz et al, 2002). In addition, HPV-16 transgenic mouse models have shown that those treated with longer durations of oestrogen were more likely to develop larger tumours and have a significantly higher number of tumours than those treated with a shorter duration (Elson et al, 2000; Brake and Lambert, 2005), supporting the human observations of a susceptible cervix to carcinogenic progression by continuous exogenous oestrogen exposure or increased endogenous oestrogen levels. If indeed oestrogen is needed for cervical carcinogenesis, close follow-up of young women and of their early pregnancies may be relevant to further understanding the role of steroids in the acquisition and persistence of HPV infections.

The influence of oestrogens on immune response may offer another explanatory effect (Mitrani-Rosenbaum et al, 1989; Arbeit et al, 1996), particularly during the follicular phase of the ovarian cycle and pregnancy, when levels of oestrogens are increased up to 3-8-fold the normal levels (Duncan et al, 1994; Marzi et al, 1996; Jabbour et al, 2008). The higher density of oestrogen receptors and their expression in the transformation zone may synergise with the effects of HPV oncoproteins, decreasing levels of cytotoxic cytokines that may down-regulate the cervical cell-mediated immune response, which favour persistent HPV infections instead of clearance (Marzi et al, 1996; Giannini et al, 1998; 2002; Jacobs et al, 2003). Additional research is needed to further understand the interaction between oestrogens and the regulation of immunomodulators, which may contribute to anti-tumour immunity.

The varying results between studies regarding the roles of AFSI and AFP may reflect the true differences between the study populations. In our study, the similar increased risks shown for AFSI and AFP may, in general, reflect the fact that in most developing countries women initiate these events at an early age, 


\section{Cervical cancer in developing countries}

KS Louie et a

Table 3 Age at first sexual intercourse and risk of cervical cancer according to various characteristics

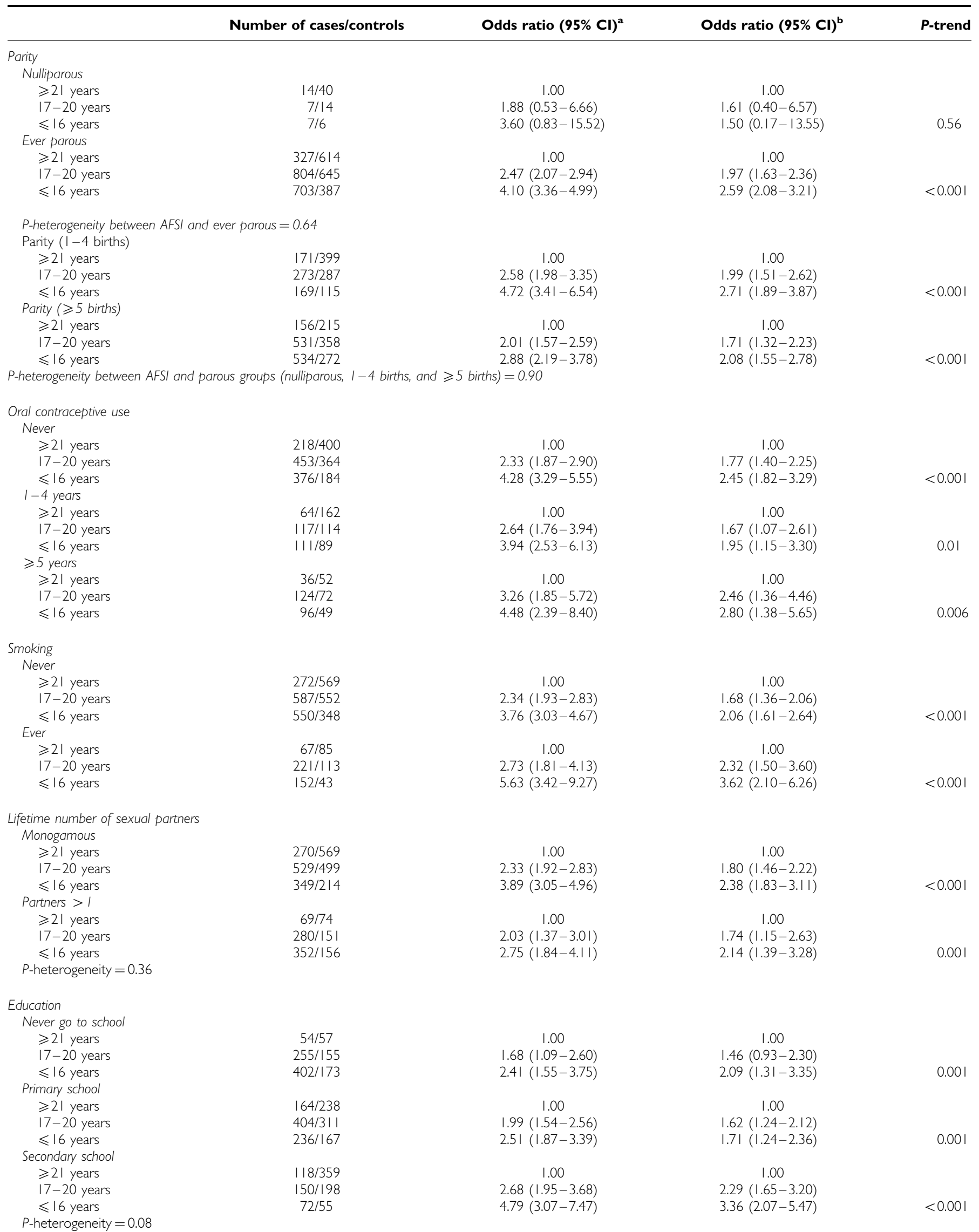




\begin{tabular}{|c|c|c|c|c|}
\hline & Number of cases/controls & Odds ratio $(95 \% \mathrm{Cl})^{\mathrm{a}}$ & Odds ratio $(95 \% \mathrm{Cl})^{\mathrm{b}}$ & P-trend \\
\hline \multicolumn{5}{|c|}{ Ever have a pap smear 12 months before study enrolment } \\
\hline$\geqslant 21$ years & $183 / 320$ & 1.00 & 1.00 & \\
\hline$\leqslant 16$ years & $416 / 205$ & $3.65(2.79-4.78)$ & $3.36(2.07-5.47)$ & $<0.001$ \\
\hline \multicolumn{5}{|l|}{ Ever } \\
\hline$\geqslant 21$ years & | 58/336 & 1.00 & 1.00 & \\
\hline
\end{tabular}

Abbreviations: $\mathrm{Cl}=$ confidence interval; $\mathrm{AFSI}=$ age at first sexual intercourse. ${ }^{\mathrm{a}}$ Adjusted for age and study centre. ${ }^{\mathrm{b}}$ Adjusted for age, study country, lifetime number of partners $(I, \geqslant 2)$, parity $(0,1-4, \geqslant 5)$, and education (never, primary, secondary).

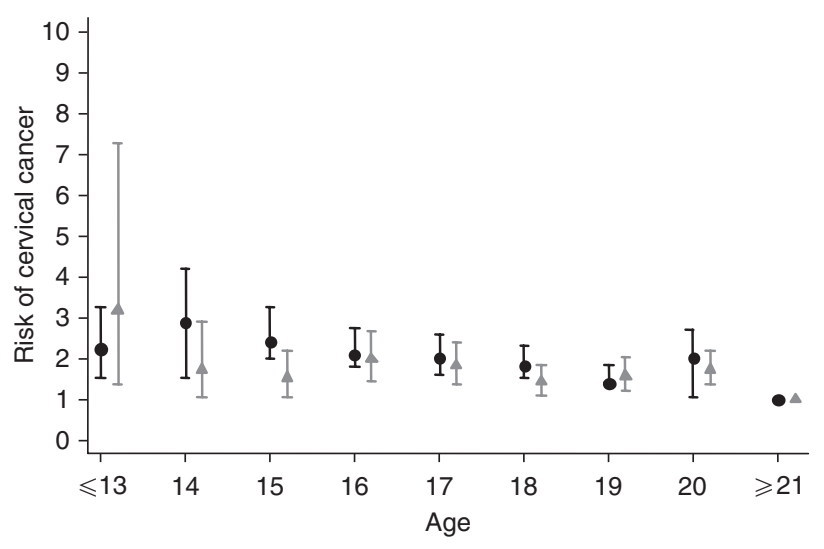

- Age at first sexual intercourse (AFSI) $\longmapsto 95 \%$ Confidence interval (CI) $\triangle$ Age at first pregnancy (AFP)

Figure I Age at first sexual intercourse and age at first pregnancy are highly correlated with the risk of invasive cervical cancer ( $P$ trend $<0.001)$. Models were adjusted for age, centre, lifetime number of sexual partners $(1,>1)$, parity $(0,1-4, \geqslant 5)$, and education (never, primary, secondary).

Table 4 Interaction between age at first pregnancy and age at first sexual intercourse in the risk of cervical cancer

\begin{tabular}{lccc}
\hline & \multicolumn{3}{c}{ Age at first pregnancy } \\
\cline { 2 - 4 } Age at sexual debut & $\geqslant \mathbf{2 1}$ & $\mathbf{1 7 - 2 0}$ & $\leqslant \mathbf{1 6}$ \\
\hline$\geqslant 21$ years & 1.00 & & \\
$17-20$ years & $1.58(1.22-2.03)$ & $1.93(1.58-2.36)$ & \\
$\leqslant 16$ years & $2.17(1.35-3.47)$ & $2.28(1.74-2.99)$ & $2.36(1.82-3.07)$ \\
\hline
\end{tabular}

and experience high parity, making their effects difficult to distinguish from one another. In contrast, results of studies in more developed countries where there is a longer latency period between sexual initiation and AFP, as in Spain, the US (Brinton et al, 1987) or Italy (Parazzini et al, 1989) tend to show an increased risk with early AFSI but not with AFP as first pregnancies tend to occur much later. It is interesting that, in countries like the UK, where the rates of teenage pregnancies are high, women with AFSI of $\leqslant 17$ years had a $2-3$-fold increased risk for cervical cancer compared with those with AFSI $\geqslant 20$ years (Green et al, 2003). Consistently, women with an early AFP of 15-19 years had a two-fold increased risk for cervical cancer compared with those with AFP $\geqslant 25$ years (Green et al, 2003). These observations merit further exploration but, in aggregate, tend to indicate a significant increase in risk of neoplastic disease when early AFSI occurs (surrogate of early HPV exposure and a period of increased cervical susceptibility) and is followed closely by an early pregnancy (surrogate of early exposure to high oestrogen levels).

Irrespective of their lifetime number of sexual partners, women have a similar increased risk of ICC with early AFSI as shown by the 2.4-fold risk among monogamous women with AFSI $\leqslant 16$ years as compared with the 2.2 -fold risk among women with $>1$ lifetime number of sexual partners. It has long been suggested that a cervical cancer risk will also depend on the sexual history of the woman's male partner in addition to her own behaviour (Skegg et al, 1982). This is particularly relevant in societies where most women are virgins at marriage and monogamous thereafter, where the incidence of cervical cancer for a population may vary depending on the behaviour of the male partner. Of our study women, $70 \%$ were monogamous. In several studies among monogamous women, the risk of cervical cancer was reported to be two to eight times for women with husbands who had multiple partners (Pridan and Lilienfeld, 1971; Buckley et al, 1981; Brinton et al, 1989). The sexual history of the male partner was not evaluated in this analysis; however, promiscuity, history of other STIS, and lack of male circumcision are factors that have been associated with the male role in cervical carcinogenesis (Castellsague et al, 2003).

In interpreting our results, we must emphasise the difficulty in fully disentangling a woman's sexual and reproductive profile in relation to her cancer risk (Schroder et al, 2003). We cannot exclude misclassification bias if AFSI and the number of sexual partners were inaccurately reported, leading to some residual confounding, However, the presence of established risk factors for ICC, use of oral contraceptives, smoking, and pap smear history did not seem to significantly affect the strength of the association between AFSI, AFP, and risk of ICC.

We examined the different stratified methodologies (unadjusted, HPV-adjusted, and HPV-positive restricted) used to evaluate the association between AFSI and risk of ICC traditionally employed in the literature. This was done to exclude any spurious association related to statistical adjustment and to clarify inconsistent findings of the association found in earlier studies. Although in strict terms restriction of analyses to HPV-positive cases and controls seemed preferable, the consistency of the results across the three different methods provides convincing evidence of the risk associated with AFSI. Furthermore, these results indicate that for the evaluation of other risk factors, adjusting for HPV status is not necessary as the adjustments do not contribute to remove any confounding effect.

Sexual practices in the world indicate that very early intercourse might be occurring in adolescents with 44,45 and $52 \%$ of girls between the ages of 13-19 years reporting being sexually experienced in Argentina, Botswana and Nigeria, respectively 
(Brown et al, 2001). In several case studies among young females, first sexual intercourse has been reported as forced in $5-15 \%$ of cases, and in some extreme cases worldwide, the estimates range from $21 \%$ among out-of-school adolescents in Botswana, $20 \%$ among secondary schools in Peru, and $41 \%$ among young urban females attending night schools in Peru. Among $15-30 \%$ of sexually active girls aged 15-19 years report forced first sexual intercourse (Brown et al, 2001). It is likely that the partners of these adolescents who report sexual coercion are adult males who are sexually experienced (Wellings et al, 2006) and at high risk of HPV exposure. Globally, these exposures might affect a high proportion of very young girls in areas of human strife, thus adding child sexual abuse to the burden of a lifetime increased risk of genital cancer.

Our study shows that women who initiate first sexual intercourse and experience their first pregnancy at a young age are at an increased risk of cervical cancer. The importance of HPV-vaccination programmes targeting young adolescents before first sexual intercourse can have a great effect in decreasing the

\section{REFERENCES}

Arbeit JM, Howley PM, Hanahan D (1996) Chronic estrogen-induced cervical and vaginal squamous carcinogenesis in human papillomavirus type 16 transgenic mice. Proc Natl Acad Sci USA 93: 2930-2935

Bosch FX, Lorincz A, Munoz N, Meijer CJ, Shah KV (2002) The causal relation between human papillomavirus and cervical cancer. J Clin Pathol 55: 244-265

Brake T, Lambert PF (2005) Estrogen contributes to the onset, persistence, and malignant progression of cervical cancer in a human papillomavirustransgenic mouse model. Proc Natl Acad Sci USA 102(7): 2490-2495

Brinton LA, Hamman RF, Huggins GR, Lehman HF, Levine RS, Mallin K, Fraumeni Jr JF (1987) Sexual and reproductive risk factors for invasive squamous cell cervical cancer. J Natl Cancer Inst 79: $23-30$

Brinton LA, Reeves WC, Brenes MM, Herrero R, Gaitan E, Tenorio F, de Britton RC, Garcia M, Rawls WE (1989) The male factor in the etiology of cervical cancer among sexually monogamous women. Int $J$ Cancer 44: 199-203

Brown A, Jejeebhoy S, Shah I, Yount K (2001) Sexual Relations Among Young People in Developing Countries Special Programme of Research, Development and Research Training in Human Reproduction, 2001 50, [11] p (WHO/RHR/01 8) World Health Organization (WHO): Geneva, Switzerland

Buckley JD, Harris RW, Doll R, Vessey MP, Williams PT (1981) Casecontrol study of the husbands of women with dysplasia or carcinoma of the cervix uteri. Lancet 2: $1010-1015$

Castellsague X, Bosch FX, Munoz N (2003) The male role in cervical cancer. Salud Publ Mex 45(Suppl 3): S345-S353

Chaouki N, Bosch FX, Munoz N, Meijer CJ, El Gueddari B, El Ghazi A, Deacon J, Castellsague X, Walboomers JM (1998) The viral origin of cervical cancer in Rabat, Morocco. Int J Cancer 75: 546-554

Chichareon S, Herrero R, Munoz N, Bosch FX, Jacobs MV, Deacon J, Santamaria M, Chongsuvivatwong V, Meijer CJ, Walboomers JM (1998) Risk factors for cervical cancer in Thailand: a case-control study. J Natl Cancer Inst 90: 50 - 57

Duncan ME, Tibaux G, Pelzer A, Mehari L, Peutherer J, Young H, Jamil Y, Darougar S, Piot P, Roggen E (1994) Teenage obstetric and gynaecological problems in an African city. Cent Afr J Med 40: 234-244

Elson DA, Riley RR, Lacey A, Thordarson G, Talamantes FJ, Arbeit JM (2000) Sensitivity of the cervical transformation zone to estrogeninduced squamous carcinogenesis. Cancer Res 60: 1267-1275

Eluf-Neto J, Booth M, Munoz N, Bosch FX, Meijer CJ, Walboomers JM (1994) Human papillomavirus and invasive cervical cancer in Brazil. Br J Cancer 69: 114-119

Giannini SL, Al Saleh W, Piron H, Jacobs N, Doyen J, Boniver J, Delvenne P (1998) Cytokine expression in squamous intraepithelial lesions of the uterine cervix: implications for the generation of local immunosuppression. Clin Exp Immunol 113: 183-189

Giannini SL, Hubert P, Doyen J, Boniver J, Delvenne P (2002) Influence of the mucosal epithelium microenvironment on Langerhans cells: incidence of cervical cancer; additional efforts are required in family planning and sexual education adapted to the extremely variable sociocultural contexts in the world.

\section{ACKNOWLEDGEMENTS}

We thank Margaret Stanley for her comments on this manuscript. This work was partially supported by Spanish public grants from the Instituto de Salud Carlos III (Grants FIS PI030240, FIS PI061246, RCESP C03/09, RTICESP C03/10, RTIC RD06/0020/0095 and CIBERESP), from the Agència de Gestió d'Ajuts Universitaris i de Recerca (AGAUR 2005SGR 00695), and from the Marató de TV3 Foundation (051530).

\section{Conflict of interest}

No conflict of interest is declared in relation to this manuscript. implications for the development of squamous intraepithelial lesions of the cervix. Int J Cancer 97: 654-659

Green J, Berrington DG, Sweetland S, Beral V, Chilvers C, Crossley B, Deacon J, Hermon C, Jha P, Mant D, Peto J, Pike M, Vessey MP (2003) Risk factors for adenocarcinoma and squamous cell carcinoma of the cervix in women aged 20-44 years: the UK National Case-Control Study of Cervical Cancer. Br J Cancer 89: 2078-2086

Hammouda D, Munoz N, Herrero R, Arslan A, Bouhadef A, Oublil M, Djedeat B, Fontaniere B, Snijders P, Meijer C, Franceschi S (2005) Cervical carcinoma in Algiers, Algeria: human papillomavirus and lifestyle risk factors. Int J Cancer 113: 483-489

Hildesheim A, Schiffman MH, Gravitt PE, Glass AG, Greer CE, Zhang T, Scott DR, Rush BB, Lawler P, Sherman ME (1994) Persistence of typespecific human papillomavirus infection among cytologically normal women. J Infect Dis 169: 235-240

Hwang LY, Ma Y, Benningfield SM, Clayton L, Hanson EN, Jay J, Jonte J, Godwin de Medina C, Moscicki AB (2009) Factors that influence the rate of epithelial maturation in the cervix in healthy young women. J Adolesc Health 44: $103-110$

IARC (2007) IARC Monogr Eval Carcinogen Risks Hum. Human Papillomaviruses, Vol. 90. International Agency for Research on Cancer: Lyon

Jabbour H, Kelly R, Fraser H, Crtichley H (2008) Endocrine regulation of menstruation. Endocr Rev 27: 17-46

Jacobs MV, Roda Husman AM, van den Brule AJ, Snijders PJ, Meijer CJ, Walboomers JM (1995) Group-specific differentiation between high- and low-risk human papillomavirus genotypes by general primer-mediated PCR and two cocktails of oligonucleotide probes. J Clin Microbiol 33: 901-905

Jacobs N, Renard I, Al Saleh W, Hubert P, Doyen J, Kedzia W, Boniver J, Delvenne P (2003) Distinct $\mathrm{T}$ cell subsets and cytokine production in cultures derived from transformation zone and squamous intraepithelial lesion biopsies of the uterine cervix. Am J Reprod Immunol 49: $6-13$

Kjaer SK, van den Brule AJC, Svare EI, Engholm G, Sherman ME, Poll PA, Walboomers JM, Bock JE, Meijer CJLM (1998) Different risk factor patterns for high-grade and low-grade intraepithelial lesions on the cervix among HPV-positive and HPV-negative young women. Int $J$ Cancer 76: 613

Marzi M, Vigano A, Trabattoni D, Villa ML, Salvaggio A, Clerici E, Clerici M (1996) Characterization of type 1 and type 2 cytokine production profile in physiologic and pathologic human pregnancy. Clin Exp Immunol 106: 127-133

Mitrani-Rosenbaum S, Tsvieli R, Tur-Kaspa R (1989) Oestrogen stimulates differential transcription of human papillomavirus type 16 in $\mathrm{SiHa}$ cervical carcinoma cells. J Gen Virol 70(Part 8): 2227-2232

Moreno V, Bosch FX, Munoz N, Meijer CJ, Shah KV, Walboomers JM, Herrero R, Franceschi S (2002) Effect of oral contraceptives on risk of 
cervical cancer in women with human papillomavirus infection: the IARC multicentric case-control study. Lancet 359: 1085-1092

Moscicki AB, Winkler B, Irwin Jr CE, Schachter J (1989) Differences in biologic maturation, sexual behavior, and sexually transmitted disease between adolescents with and without cervical intraepithelial neoplasia. J Pediatr 115: $487-493$

Munoz N, Bosch FX, de Sanjose S, Vergara A, del Moral A, Munoz MT, Tafur L, Gili M, Izarzugaza I, Viladiu P (1993) Risk factors for cervical intraepithelial neoplasia grade III/carcinoma in situ in Spain and Colombia. Cancer Epidemiol Biomarkers Prev 2: $423-431$

Munoz N, Franceschi S, Bosetti C, Moreno V, Herrero R, Smith JS, Shah KV, Meijer CJ, Bosch FX (2002) Role of parity and human papillomavirus in cervical cancer: the IARC multicentric case-control study. Lancet 359: $1093-1101$

Ngelangel C, Munoz N, Bosch FX, Limson GM, Festin MR, Deacon J, Jacobs MV, Santamaria M, Meijer CJ, Walboomers JM (1998) Causes of cervical cancer in the Philippines: a case-control study. J Natl Cancer Inst 90: $43-49$

Parazzini F, La Vecchia C, Negri E, Cecchetti G, Fedele L (1989) Reproductive factors and the risk of invasive and intraepithelial cervical neoplasia. Br J Cancer 59: 805-809

Pridan H, Lilienfeld AM (1971) Carcinoma of the cervix in Jewish women in Israel, 1960-1967. An epidemiological study. Isr J Med Sci 7: $1465-1470$

Roda Husman AM, Walboomers JM, van den Brule AJ, Meijer CJ, Snijders PJ (1995) The use of general primers GP5 and GP6 elongated at their $3^{\prime}$ ends with adjacent highly conserved sequences improves human papillomavirus detection by PCR. J Gen Virol 76(Part 4): 1057- 1062

Rolon PA, Smith JS, Munoz N, Klug SJ, Herrero R, Bosch X, Llamosas F, Meijer CJ, Walboomers JM (2000) Human papillomavirus infection and invasive cervical cancer in Paraguay. Int J Cancer 85: 486-491

Schroder KE, Carey MP, Vanable PA (2003) Methodological challenges in research on sexual risk behavior: II. Accuracy of self-reports. Ann Behav Med 26: $104-123$

Shai A, Brake T, Somoza C, Lambert PF (2007) The human papillomavirus E6 oncogene dysregulates the cell cycle and contributes to cervical carcinogenesis through two independent activities. Cancer Res 67: 1626-1635

Shai A, Pitot HC, Lambert PF (2008) p53 Loss synergizes with estrogen and papillomaviral oncogenes to induce cervical and breast cancers. Cancer Res 68: $2622-2631$

Singer A, Monaghan J (2000) Colcoscopy of the normal cervix: a prerequisite to establish the diagnosis of cervical precancer. In Lower Genital Tract Precancer: Coloscopy, Pathology, and Treatment Singer A, Monaghan J (eds) pp 43-70 Blackwell Sciences Ltd.: Oxford, UK

Skegg DC, Corwin PA, Paul C, Doll R (1982) Importance of the male factor in cancer of the cervix. Lancet 2: $581-583$

Walboomers J, Melkert P, van de Brule A, Snijders P, Meijer C (1992) The polymerase chain reaction for human papillomavirus screening in diagnostic cytopathology of the cervix. In Diagnostic Molecular Pathology: A Practical Approach, Herrington CS, McGee OD, McGee Jo (eds) pp 152-172. Oxford University Press: Oxford

Wellings K, Collumbien M, Slaymaker E, Singh S, Hodges Z, Patel D, Bajos N (2006) Sexual behaviour in context: a global perspective. Lancet 368: $1706-1728$ 